\title{
Analisis Kestabilan Model Predator-Prey dengan Adanya Faktor Tempat Persembunyian Menggunakan Fungsi Respon Holling Tipe III
}

\author{
Riris Nur Patria Putri ${ }^{1}$, Windarto ${ }^{2, *}, \&$ Cicik Alfiniyah ${ }^{3}$ \\ Departemen Matematika, Fakultas Sains dan Teknologi, Universitas Airlangga \\ *Corresponding author: windarto@fst.unair.ac.id
}

\begin{abstract}
Abstrak. Predation is interaction between predator and prey, where predator preys prey. So predators can grow, develop, and reproduce. In order for prey to avoid predators, then prey needs a refuge. In this thesis, a predator-prey model with refuge factor using Holling type III response function which has three populations, i.e. prey population in the refuge, prey population outside the refuge, and predator population. From the model, three equilibrium points were obtained, those are extinction of the three populations which is unstable, while extinction of predator population and coexistence are asymptotic stable under certain conditions. The numerical simulation results show that refuge have an impact the survival of the prey.
\end{abstract}

Keywords: Predator-prey model, Refuge, Holling type III, Response Function, Stability

\section{Pendahuluan}

Biosfer merupakan hal yang penting bagi kehidupan makhluk hidup, yang mana mencakup komponen biotik dan abiotik. Komponen abiotik terdiri dari udara, daratan, air, cahaya, iklim, cuaca, suhu, angin, kelembapan, kandungan mineral, kandungan keasaman, dan salinitas. Sedangkan komponen biotik mencakup semua makhluk hidup yang tinggal di suatu lingkungan, seperti manusia, hewan, tumbuhan, dan mikroorganisme. Dengan adanya komponen-komponen tersebut, sangat memungkinkan terjadi interaksi di dalamnya. Salah satunya adalah interaksi antar sesama komponen biotik, contohnya adalah predasi [1].

Predasi merupakan interaksi antara pemangsa (predator) dan mangsa (prey), dimana predator memangsa prey. Dalam predasi, predator mengambil energi dari prey untuk tumbuh dan bereproduksi, sedangkan prey merupakan organisme yang dirugikan atau dikonsumsi oleh predator [2]. Jika hal ini terjadi terus-menerus, maka prey akan mengalami kepunahan. Adapun cara supaya prey terhindar dari kepunahan, salah satunya dengan mencari tempat persembunyian. Tempat persembunyian dapat mempengaruhi dinamika populasi predator-prey. Tempat persembunyian prey memiliki dampak yang sangat besar terhadap koeksistensi predator dan prey dengan cara mengurangi kepunahan pada prey. Jenis ekosistem ini dapat ditemukan pada ekosistem terumbu karang [3].

Penelitian pemodelan matematika mengenai predator-prey telah banyak dilakukan. Kar [4] memodelkan dan menganalisa sistem prey-predator dengan memperhatikan adanya 
tempat persembunyian mangsa dan pemanenan di kedua spesies. Dubey [5] memodelkan model predator-prey dengan memperhatikan adanya area persembunyian yang dilindungi. Wang dkk [6] memodelkan piramida biomassa terbalik dan tempat persembunyian pada ekosistem. Berezovskaya dkk [7] mengamati peran penyebaran mangsa dan tempat persembunyian pada dinamika predator-prey. Singh dkk [8] memodelkan struktur biomassa ikan pada terumbu karang yang hampir murni dan degradasi karena adanya penangkapan ikan. Wang dkk [3] meneliti dinamika predatorprey dan piramida biomassa dengan faktor tempat persembunyian.

Dari beberapa alasan di atas, penulis ingin melihat bagaimana model predator-prey dengan adanya faktor tempat persembunyian menggunakan fungsi respon Holling tipe III dari waktu ke waktu. Selain itu, penulis ingin mengetahui bagaimana titik setimbang yang dihasilkan dari model predator-prey tersebut, dan juga ingin mengetahui bagaimana kestabilan dari model predator-prey dengan adanya faktor tempat persembunyian menggunakan fungsi respon Holling tipe III di sekitar titik setimbangnya. Adapun batasan masalah yang penulis gunakan dalam penulisan ini yakni penulis hanya memperhatikan model predator-prey pada terumbu karang yang ditulis oleh Wang dkk [3]. Sehingga penulis tidak memperhatikan model predator-prey populasi hewan lainnnya.

\section{Model Matematika}

Model dasar predator-prey ini dirujuk dari artikel ilmiah Wang dkk. [3]. Model predatorprey ini memiliki tiga kompartemen, yaitu $x_{r}, x$, dan $y$ dimana secara berurutan menunjukkan kepadatan populasi prey yang berada di dalam tempat perlindungan, kepadatan populasi prey yang berada di luar tempat perlindungan, dan kepadatan populasi predator. Dalam kasus ini terdapat beberapa asumsi sebagai berikut:

a. Prey hanya dapat menemukan makanan dan tumbuh di dalam tempat perlindungan, dan kapasitas pendukung merupakan fungsi naik dari ukuran tempat persembunyian.

b. Pertumbuhan prey di dalam tempat perlindungan merupakan pertumbuhan logistik.

c. Pada saat ketiadaan prey, predator turun secara eksponensial.

d. Predator hanya dapat memangsa prey yang berada di luar tempat perlindungan.

e. Prey dapat migrasi keluar masuk tempat perlindungan, dan hanya laju imigrasi yang bergantung terhadap ukuran tempat perlindungan.

f. Laju kematian prey yang berada di luar tempat persembunyian diabaikan.

Variabel dan parameter yang akan digunakan pada model predator-prey dengan adanya faktor tempat persembunyian menggunakan fungsi respon holling tipe III akan diberikan sebagai berikut: 
Tabel 1 Definisi Variabel Model Predador-Prey

\begin{tabular}{|c|c|c|}
\hline Variabel & Keterangan & Satuan \\
\hline$x_{r}$ & $\begin{array}{c}\text { Kepadatan populasi prey yang berada di dalam } \\
\text { tempat persembunyian }\end{array}$ & $\mathrm{kg} / \mathrm{m}^{3}$ \\
\hline$x$ & $\begin{array}{c}\text { Kepadatan populasi prey yang berada di luar } \\
\text { tempat persembunyian }\end{array}$ & $\mathrm{kg} / \mathrm{m}^{3}$ \\
\hline$y$ & Kepadatan populasi predator & $\mathrm{kg} / \mathrm{m}^{3}$ \\
\hline
\end{tabular}

Tabel 2 Definisi Parameter Model Predador-Prey

\begin{tabular}{|c|c|c|}
\hline Parameter & Keterangan & Satuan \\
\hline$a$ & $\begin{array}{c}\text { Laju pertumbuhan per kapita dari prey yang berada di } \\
\text { dalam tempat persembunyian }\end{array}$ & $1 /$ hari \\
\hline$K(r)$ & $\begin{array}{c}\text { Kapasitas pendukung prey di dalam tempat } \\
\text { persembunyian yang bergantung terhadap ukuran tempat } \\
\text { persembunyian dengan } K(r)=K r\end{array}$ & $\mathrm{~kg} / \mathrm{m}^{3}$ \\
\hline$r$ & Ukuran tempat persembunyian prey & - \\
\hline$\alpha$ & Laju emigrasi dari tempat persembunyian & $1 / \mathrm{hari}$ \\
\hline$\beta(r)$ & $\begin{array}{c}\text { Laju imigrasi ke tempat persembunyian yang bergantung } \\
\text { terhadap ukuran tempat persembunyian dengan } \\
\beta r^{2}\end{array}$ & $1 / \mathrm{hari}^{2}+\mathrm{r}^{2}$ \\
\hline$\gamma$ & Laju maksimum predasi & $\frac{\mathrm{m}^{6} / \mathrm{kg}^{2}}{\mathrm{hari}^{2}}$ \\
\hline$\theta$ & Tingkat kejenuhan predator & $\mathrm{m}^{6} / \mathrm{kg}^{2}$ \\
\hline$c$ & Nilai konversi prey yang diubah menjadi predator & - \\
\hline$d$ & Laju kematian per kapita predator & $1 / \mathrm{hari}^{2}$ \\
\hline
\end{tabular}

Pada model predator-prey dengan adanya faktor tempat persembunyian menggunakan fungsi respon Holling tipe III diasumsikan nilai variabel $x_{r}, x, y \geq 0$ dan nilai parameter bernilai positif.

Berikut adalah model predator-prey dengan adanya faktor tempat persembunyian yang digunakan pada penulisan ini:

$$
\begin{aligned}
& \frac{d x_{r}}{d t}=a x_{r}\left[1-\frac{x_{r}}{K r}\right]-\alpha x_{r}+\frac{\beta r^{2}}{\xi^{2}+r^{2}} x \\
& \frac{d x}{d t}=\alpha x_{r}-\frac{\beta r^{2}}{\xi^{2}+r^{2}} x-\frac{\gamma x^{2}}{1+\theta x^{2}} y \\
& \frac{d y}{d t}=c \frac{\gamma x^{2}}{1+\theta x^{2}} y-d y
\end{aligned}
$$


Pada bagian ini akan dibahas megenai analisis kestabilan lokal dari titik setimbang kepunahan ketiga populasi, titik setimbang kepunahan predator, serta titik setimbang koeksistensi.

\subsection{Titik Setimbang}

Berdasarkan Abell dan Braselton [9], titik setimbang merupakan titik pada saat kondisi ketika perubahan jumlah populasi tertentu sepanjang satuan waktu adalah nol. Keadaan setimbang pada model predator-prey ini terpenuhi saat $\frac{d x_{r}}{d t}=\frac{d x}{d t}=\frac{d y}{d t}=0$.

Titik setimbang kepunahan ketiga populasi merupakan titik setimbang pada saat kondisi populasi prey yang berada di dalam tempat persembunyian, populasi prey yang berada di luar tempat persembunyian, dan populasi predator sepanjang satuan waktu mengalami kepunahan. Kondisi ini artinya $x_{r}=0, x=0, y=0$. Oleh karena itu, diperoleh titik setimbang $E_{0}=\left(x_{r 0}, x_{0}, y_{0}\right)=(0,0,0)$.

Titik setimbang kepunahan predator merupakan titik setimbang pada saat kondisi populasi predator mengalami kepunahan, sehingga tidak adanya predator yang memangsa prey yang berada di luar tempat persembunyian. Kondisi ini terjadi ketika $x_{r} \neq 0, x \neq 0, y=0$. Sehingga dapat dimisalkan titik setimbang kepunahan predator adalah $E_{1}=\left(x_{r 1}, x_{1}, y_{1}\right)=\left(x_{r 1}, x_{1}, 0\right)$. Dari persamaan (1), (2), (3) diperoleh $\frac{d x_{r}}{d t}=$ $\frac{d x}{d t}=\frac{d y}{d t}=0$. Sehingga diperoleh titik setimbang kepunahan predator $E_{1}=$ $\left(x_{r 1}, x_{1}, y_{1}\right)=\left(K r, \frac{\alpha K r\left(\xi^{2}+r^{2}\right)}{\beta r^{2}}, 0\right)$.

Titik setimbang koeksistensi merupakan titik setimbang ketika kondisi populasi prey yang berada di dalam tempat persembunyian, populasi prey yang berada di luar tempat persembunyian, dan populasi predator dapat hidup berdampingan dalam suatu ekosistem. Kondisini ini terjadi ketika $x_{r} \neq 0, x \neq 0, y \neq 0$. Dari persamaan (1), (2), (3) didapatkan $\frac{d x_{r}}{d t}=\frac{d x}{d t}=\frac{d y}{d t}=0$ sehingga titik setimbang koeksistensi $E_{2}=\left(x_{r 2}, x_{2}, y_{2}\right)$ dengan didapat sebagai berikut:

$$
\begin{aligned}
& x_{2}=\sqrt{\frac{d}{c \gamma-d \theta}} \\
& x_{r 2}=K r\left[\frac{(a-\alpha)+\sqrt{(a-\alpha)^{2}+4 \frac{a \beta r}{K\left(\xi^{2}+r^{2}\right)} x_{2}}}{2 a}\right] \\
& y_{2}=\frac{c}{d}\left(\frac{\alpha K r}{2 a}\left[(a-\alpha)+\sqrt{(a-\alpha)^{2}+4 \frac{a \beta r}{K\left(\xi^{2}+r^{2}\right)} x_{2}}\right]-\frac{\beta r^{2}}{\xi^{2}+r^{2}} x_{2}\right)
\end{aligned}
$$


Titik setimbang koeksistensi ada jika $c \gamma-d \theta>0, \quad a-\alpha>0, \quad$ dan $\alpha K r\left[\frac{(a-\alpha)+\sqrt{(a-\alpha)^{2}+4 \frac{a \beta r}{K\left(\xi^{2}+r^{2}\right)} x_{2}}}{2 a}\right]-\frac{\beta r^{2}}{\xi^{2}+r^{2}} x_{2}>0$.

\subsection{Analisis Kestabilan di Sekitar Titik Setimbang}

Pada bagian ini akan dilakukan analisis kestabilan lokal dari masing-masing titik setimbang. Analisis ini dilakukan untuk mengetahui dinamika perilaku sistem pada model. Analisis kestabilan lokal didekati dengan menggunakan nilai eigen $(\lambda)$, sehingga kestabilan asimtotis lokal dari model predator-prey dengan adanya faktor tempat persembunyian menggunakan fungsi respon Holling tipe III di titik setimbang $E_{0}, E_{1}$, dan $E_{2}$ dilakukan dengan menggunakan matriks Jacobian. Dari persamaan (1), (2), dan (3) didapatkan Matriks Jacobian sebagai berikut:

$J=\left[\begin{array}{ccc}a-\alpha-\frac{2 a x_{r}}{K r} & \frac{\beta r^{2}}{\xi^{2}+r^{2}} & 0 \\ \alpha & -\frac{\beta r^{2}}{\xi^{2}+r^{2}}-\frac{2 \gamma x y\left[\left(1+\theta x^{2}\right)-\theta x^{2} y\right]}{\left(1+\theta x^{2}\right)^{2}} & -\frac{\gamma x^{2}}{1+\theta x^{2}} \\ 0 & \frac{2 c \gamma x y\left[\left(1+\theta x^{2}\right)-\theta x^{2} y\right]}{\left(1+\theta x^{2}\right)^{2}} & \frac{c \gamma x^{2}}{1+\theta x^{2}}-d\end{array}\right]$

Selanjutnya, akan dianalisis kestabilan dari titik setimbang kepunahan ketiga populasi, kepunahan predator, dan koeksistensi.

a. Kestabilan lokal titik setimbang kepunahan ketiga populasi

Matriks Jacobian untuk titik setimbang kepunahan ketiga populasi $E_{0}=\left(x_{r 0}, x_{0}, y_{0}\right)=$ $(0,0,0)$ adalah sebagai berikut.

$$
J\left(E_{0}\right)=\left[\begin{array}{ccc}
a-\alpha & \frac{\beta r^{2}}{\xi^{2}+r^{2}} & 0 \\
\alpha & -\frac{\beta r^{2}}{\xi^{2}+r^{2}} & 0 \\
0 & 0 & -d
\end{array}\right]
$$

Kemudian matriks $J\left(E_{0}\right)$ di atas dapat dibentuk persamaaan karakteristik dengan menggunakan $\operatorname{det}\left(\lambda I-J\left(E_{0}\right)\right)=0$ sebagai berikut.

$$
\Leftrightarrow(\lambda+d)\left[(\lambda-a+\alpha)\left(\lambda+\frac{\beta r^{2}}{\xi^{2}+r^{2}}\right)-\frac{\alpha \beta r^{2}}{\xi^{2}+r^{2}}\right]=0
$$

Berdasarkan persamaan (8), diperoleh nilai eigen $\lambda_{1}=-d$ dan akar-akar dari persamaan berikut.

$$
\lambda^{2}+b_{1} \lambda+b_{2}=0
$$




$$
\begin{aligned}
& b_{1}=\alpha-a+\frac{\beta r^{2}}{\xi^{2}+r^{2}} \\
& b_{2}=-\frac{a \beta r^{2}}{\xi^{2}+r^{2}}
\end{aligned}
$$

Titik setimbang kepunahan ketiga populasi tersebut akan stabil asimtotis jika dan hanya jika persamaan (9) mempunyai akar-akar bagian real negatif. Dari penjelasan sebelumnya jelas bahwa $\lambda_{1}$ bernilai negatif sebab semua parameter pada model berniali positif. Selanjutnya, akan ditentukan syarat agar persamaan (9) memiliki akar-akar yang bagian realnya negatif, yaitu dengan menggunakan kriteria Routh Hurwitz.

Persamaan karakteristik (9) akan memiliki akar-akar yang bagian realnya negatif jika nilai dari $b_{1}, b_{2}>0$.

i. Koefisien $b_{1}$ akan bernilai lebih dari nol apabila memenuhi $\alpha+\frac{\beta r^{2}}{\xi^{2}+r^{2}}>a$.

ii. Karena semua nilai parameter bernilai positif, maka dapat dipastikan bahwa $b_{2}<$ 0 .

Berdasarkan uraian di atas diperoleh bahwa titik setimbang kepunahan ketiga populasi $E_{0}$ tidak stabil.

\section{b. Kestabilan lokal titik setimbang kepunahan predator}

Matriks Jacobian untuk titik setimbang kepunahan predator $E_{1}=\left(x_{r_{1}}, x_{1}, 0\right)$ adalah sebagai berikut.

$$
J\left(E_{1}\right)=\left[\begin{array}{ccc}
-a-\alpha & \frac{\beta r^{2}}{\xi^{2}+r^{2}} & 0 \\
\alpha & -\frac{\beta r^{2}}{\xi^{2}+r^{2}} & -\frac{\gamma\left(\alpha K r\left(\xi^{2}+r^{2}\right)\right)^{2}}{\left(\beta r^{2}\right)^{2}+\theta\left(\alpha K r\left(\xi^{2}+r^{2}\right)\right)^{2}} \\
0 & 0 & \frac{c \gamma\left(\alpha K r\left(\xi^{2}+r^{2}\right)\right)^{2}}{\left(\beta r^{2}\right)^{2}+\theta\left(\alpha K r\left(\xi^{2}+r^{2}\right)\right)^{2}}-d
\end{array}\right]
$$

Kemudian matriks $J\left(E_{1}\right)$ di atas dapat dibentuk persamaaan karakteristik dengan menggunakan $\operatorname{det}\left(\lambda I-J\left(E_{1}\right)\right)=0$ sebagai berikut.

$$
\Leftrightarrow\left[\lambda-\frac{c \gamma\left(\alpha K r\left(\xi^{2}+r^{2}\right)\right)^{2}}{\left(\beta r^{2}\right)^{2}+\theta\left(\alpha K r\left(\xi^{2}+r^{2}\right)\right)^{2}}+d\right]\left[(\lambda+a+\alpha)\left(\lambda+\frac{\beta r^{2}}{\xi^{2}+r^{2}}\right)-\frac{\alpha \beta r^{2}}{\xi^{2}+r^{2}}\right]=0
$$

Berdasarkan persamaan (11), diperoleh nilai eigen $\lambda_{1}=\frac{c \gamma\left(\alpha K r\left(\xi^{2}+r^{2}\right)\right)^{2}}{\left(\beta r^{2}\right)^{2}+\theta\left(\alpha K r\left(\xi^{2}+r^{2}\right)\right)^{2}}-d$ dan akar-akar dari persamaan berikut.

$$
\begin{aligned}
& \lambda^{2}+b_{1} \lambda+b_{2}=0 \\
& b_{1}=\alpha+a+\frac{\beta r^{2}}{\xi^{2}+r^{2}}
\end{aligned}
$$


$b_{2}=\frac{a \beta r^{2}}{\xi^{2}+r^{2}}$

Titik setimbang kepunahan predator tersebut akan stabil asimtotis jika dan hanya jika persamaan (12) mempunyai akar-akar bagian real negatif. Karena semua nilai parameter bernilai positif, maka dari penjelasan sebelumnya nilai $\lambda_{1}$ akan bernilai negatif apabila $\frac{c \gamma\left(\alpha K r\left(\xi^{2}+r^{2}\right)\right)^{2}}{\left(\beta r^{2}\right)^{2}+\theta\left(\alpha K r\left(\xi^{2}+r^{2}\right)\right)^{2}}<d$. Selanjutnya, akan ditentukan syarat agar persamaan (12) memiliki akar-akar yang bagian realnya negatif, yaitu dengan menggunakan kriteria Routh Hurwitz.

Persamaan karakteristik (12) akan memiliki akar-akar yang bagian realnya negatif jika nilai dari $b_{1}, b_{2}>0$.

i. Karena semua nilai parameter bernilai positif, maka dapat dipastikan bahwa $b_{1}>$ 0 .

ii. Karena semua nilai parameter bernilai positif, maka dapat dipastikan bahwa $b_{2}>$ 0 .

Berdasarkan uraian di atas diperoleh bahwa titik setimbang kepunahan predator $E_{1}$ stabil asimtotis jika $\frac{c \gamma\left(\alpha K r\left(\xi^{2}+r^{2}\right)\right)^{2}}{\left(\beta r^{2}\right)^{2}+\theta\left(\alpha K r\left(\xi^{2}+r^{2}\right)\right)^{2}}<d$.

\section{c. Kestabilan lokal titik setimbang koeksistensi}

Matriks Jacobian untuk titik setimbang koeksistensi $E_{2}=\left(x_{r_{2}}, x_{2}, y_{2}\right)$ adalah sebagai berikut.

$J\left(E_{2}\right)=\left[\begin{array}{ccc}a-\alpha-\frac{2 a x_{r}}{K r} & \frac{\beta r^{2}}{\xi^{2}+r^{2}} & 0 \\ \alpha & -\frac{\beta r^{2}}{\xi^{2}+r^{2}}-\frac{2 \gamma x y\left[\left(1+\theta x^{2}\right)-\theta x^{2} y\right]}{\left(1+\theta x^{2}\right)^{2}} & -\frac{\gamma x^{2}}{1+\theta x^{2}} \\ 0 & \frac{2 c \gamma x y\left[\left(1+\theta x^{2}\right)-\theta x^{2} y\right]}{\left(1+\theta x^{2}\right)^{2}} & \frac{c \gamma x^{2}}{1+\theta x^{2}}-d\end{array}\right]$

Dengan menggunakan kondisi kesetimbangan koeksistensi di dapat matriks $J\left(E_{2}\right)$ sebagai berikut:

$$
J\left(E_{2}\right)=\left[\begin{array}{ccc}
a-\alpha-\frac{2 a x_{r}}{K r} & \frac{\beta r^{2}}{\xi^{2}+r^{2}} & 0 \\
\alpha & -\frac{\beta r^{2}}{\xi^{2}+r^{2}}-\frac{2 \gamma x y\left[\left(1+\theta x^{2}\right)-\theta x^{2} y\right]}{\left(1+\theta x^{2}\right)^{2}} & -\frac{d}{c} \\
0 & \frac{2 c \gamma x y\left[\left(1+\theta x^{2}\right)-\theta x^{2} y\right]}{\left(1+\theta x^{2}\right)^{2}} & 0
\end{array}\right]
$$


Kemudian matriks $J\left(E_{2}\right)$ di atas dapat dibentuk persamaaan karakteristik dengan menggunakan $\operatorname{det}\left(\lambda I-J\left(E_{2}\right)\right)=0$ sebagai berikut:

$$
\begin{aligned}
& \lambda^{3}+b_{1} \lambda^{2}+b_{2} \lambda+b_{3}=0 \\
& b_{1}=\frac{1}{K r x_{r} x\left(\xi^{2}+r^{2}\right)\left(1+\theta x^{2}\right)^{2}}\left(\operatorname{Kar}^{3} \theta^{2} x_{r}{ }^{2} x^{4}+K \beta r^{3} \theta^{2} x^{6}-K r^{3} \gamma \theta x_{r} x^{4} y\right. \\
& +2 K a r^{3} \theta x_{r}{ }^{2} x^{2}+2 K r^{3} \beta \theta x^{4}+K r^{3} \gamma x_{r} x^{2} y+K a r^{3} x_{r}{ }^{2}+K \beta r^{3} x^{2} \\
& +a r^{2} \theta^{2} x_{r}{ }^{2} x^{5}+2 a r^{2} \theta x_{r}{ }^{2} x^{3}+a r^{2} x_{r}{ }^{2} x+2 \operatorname{Kar} \theta \xi^{2} x_{r}{ }^{2} x^{2} \\
& +\operatorname{Kar} \theta^{2} \xi^{2} x_{r}{ }^{2} x^{4}-\operatorname{Kr} \gamma \theta \xi^{2} x_{r} x^{4} y+\operatorname{Kr} \gamma \xi^{2} x_{r} x^{2} y+\operatorname{Kar}^{2} x_{r}{ }^{2} \\
& \left.+a \theta^{2} \xi^{2} x_{r}^{2} x^{5}+2 a \theta \xi^{2} x_{r}^{2} x^{3}+a \xi^{2} x_{r}{ }^{2} x\right) \\
& b_{2}=\frac{1}{K r x_{r} x\left(\xi^{2}+r^{2}\right)\left(1+\theta x^{2}\right)^{2}}\left(\operatorname{Kar}^{3} \beta \theta^{2} x_{r} x^{5}-K r^{3} \alpha \beta \theta^{2} x_{r} x^{5}-K r^{3} \beta \gamma \theta x^{5} y\right. \\
& +2 \operatorname{Kar}^{3} \beta \theta x_{r} x^{3}-2 K r^{3} \alpha \beta \theta x_{r} x^{3}+K r^{3} \beta \gamma x^{3} y+2 K d r^{3} \gamma x_{r} x^{2} y \\
& +\operatorname{Kar}^{3} \beta x_{r} x-K r^{3} \alpha \beta x_{r} x+a^{2} r^{2} \theta^{2} x_{r}{ }^{3} x^{4}-a r^{2} \gamma \theta x_{r}{ }^{2} x^{4} y \\
& +2 a^{2} r^{2} \theta x_{r}{ }^{3} x^{2}+a r^{2} \gamma x_{r}{ }^{2} x^{2} y+a^{2} r^{2} x_{r}{ }^{3}+2 K d r \gamma \xi^{2} x_{r} x^{2} y \\
& +a^{2} \theta^{2} \xi^{2} x_{r}{ }^{3} x^{4}-a \gamma \theta \xi^{2} x_{r}{ }^{2} x^{4} y+2 a^{2} \theta \xi^{2} x_{r}{ }^{3} x^{2}+a \gamma \xi^{2} x_{r}{ }^{2} x^{2} y \\
& \left.+a^{2} \xi^{2} x_{r}^{3}\right) \\
& b_{3}=\frac{1}{K r x_{r}\left(\xi^{2}+r^{2}\right)\left(1+\theta x^{2}\right)^{2}}\left(2 d \gamma x y\left(K r^{3} \beta x+a r^{2} x_{r}{ }^{2}+a \xi^{2} x_{r}{ }^{2}\right)\right)
\end{aligned}
$$

Titik setimbang koeksistensi akan stabil asimtotis jika dan hanya jika persamaan (15) mempunyai akar-akar bagian real negatif. Selanjutnya, akan ditentukan syarat agar persamaan memiliki akar-akar yang bagian realnya negatif, yaitu dengan menggunakan kriteria Routh-Hurwitz.

Persamaan karakteristik (15) akan memiliki akar-akar yang bagian real negatif jika nilai dari $b_{1}, b_{2}, b_{3},\left(b_{1} b_{2}-b_{3}\right)>0$.

i. Agar memenuhi $b_{1}>0$, maka harus memenuhi syarat adalah sebagai berikut:

$K a r^{3} \theta^{2} x_{r}{ }^{2} x^{4}+K \beta r^{3} \theta^{2} x^{6}+2 K a r^{3} \theta x_{r}{ }^{2} x^{2}+2 K r^{3} \beta \theta x^{4}+K r^{3} \gamma x_{r} x^{2} y+$

$K a r^{3} x_{r}{ }^{2}+K \beta r^{3} x^{2}+a r^{2} \theta^{2} x_{r}{ }^{2} x^{5}+2 a r^{2} \theta x_{r}{ }^{2} x^{3}+a r^{2} x_{r}{ }^{2} x+$ $2 \operatorname{Kar} \theta \xi^{2} x_{r}{ }^{2} x^{2}+\operatorname{Kar}^{2} \xi^{2} x_{r}{ }^{2} x^{4}+K r \gamma \xi^{2} x_{r} x^{2} y+\operatorname{Kar}^{2} x_{r}{ }^{2}+$ $a \theta^{2} \xi^{2} x_{r}{ }^{2} x^{5}+2 a \theta \xi^{2} x_{r}{ }^{2} x^{3}+a \xi^{2} x_{r}{ }^{2} x>K r^{3} \gamma \theta x_{r} x^{4} y+K r \gamma \theta \xi^{2} x_{r} x^{4} y$

ii. Syarat agar $b_{2}>0$ adalah sebagai berikut:

$$
\begin{aligned}
& \operatorname{Kar}^{3} \beta \theta^{2} x_{r} x^{5}+2 \operatorname{Kar}^{3} \beta \theta x_{r} x^{3}+K r^{3} \beta \gamma x^{3} y+2 K d r^{3} \gamma x_{r} x^{2} y+ \\
& \operatorname{Kar}^{3} \beta x_{r} x+a^{2} r^{2} \theta^{2} x_{r}{ }^{3} x^{4}+2 a^{2} r^{2} \theta x_{r}{ }^{3} x^{2}+a r^{2} \gamma x_{r}{ }^{2} x^{2} y+a^{2} r^{2} x_{r}{ }^{3}+ \\
& 2 K d r \gamma \xi^{2} x_{r} x^{2} y+a^{2} \theta^{2} \xi^{2} x_{r}{ }^{3} x^{4}+2 a^{2} \theta \xi^{2} x_{r}{ }^{3} x^{2}+a \gamma \xi^{2} x_{r}{ }^{2} x^{2} y+a^{2} \xi^{2} x_{r}{ }^{3}> \\
& \operatorname{Kr}^{3} \alpha \beta \theta^{2} x_{r} x^{5}+K r^{3} \beta \gamma \theta x^{5} y+2 K r^{3} \alpha \beta \theta x_{r} x^{3}+K r^{3} \alpha \beta x_{r} x+ \\
& a r^{2} \gamma \theta x_{r}{ }^{2} x^{4} y+a \gamma \theta \xi^{2} x_{r}{ }^{2} x^{4} y
\end{aligned}
$$

iii. Karena $x_{r}, x, y>0$ dan nilai parameter bernilai positif, maka $b_{3}>0$.

Dalam menentukan syarat $\left(b_{1} b_{2}-b_{3}\right)>0$ untuk menentukan kestabilan titik setimbang koeksistensi sulit untuk dilakukan secara analitik, maka dilakukan secara numerik 
menggunakan software MATLAB. Simulasi ini dilakukan dengan memberi nilai parameter dan empat nilai awal untuk $x_{r}(0), x(0)$, dan $y(0)$ yang diketahui. Berikut adalah tabel nilai awal dan nilai parameter yang digunakan. Simulasi ini hanya dilakukan pada waktu $t=0$ sampai $t=50000$ hari.

Tabel 3 Nilai Awal untuk Bidang Fase Koeksistensi

\begin{tabular}{|c|c|c|c|c|}
\hline Nilai Awal & $x_{r}(0)$ & $x(0)$ & $y(0)$ & Warna \\
\hline 1 & 0,20 & 0,15 & 0,10 & Hijau \\
\hline 2 & 0,30 & 0,25 & 0,20 & Biru \\
\hline 3 & 0,40 & 0,35 & 0,30 & Merah \\
\hline
\end{tabular}

Tabel 4 Nilai Parameter Model Predator-Prey Saat Kondisi Koeksistensi

\begin{tabular}{|c|c|c|}
\hline Parameter & Nilai Parameter & Sumber \\
\hline$a$ & 0,6 & Asumsi \\
\hline$K$ & 0,8 & Wang dkk (2018) \\
\hline$r$ & 1 & Asumsi \\
\hline$\alpha$ & 0,035 & Wang dkk (2018) \\
\hline$\beta$ & 0,0119 & Wang dkk (2018) \\
\hline$\gamma$ & 0,112 & Asumsi \\
\hline$c$ & 0,01 & Asumsi \\
\hline$d$ & 0,0007 & Asumsi \\
\hline$\xi$ & 1 & Asumsi \\
\hline$\theta$ & 0,1 & Asumsi \\
\hline
\end{tabular}

Berdasarkan nilai parameter pada Tabel 3, berikut ini adaah simulasi bidang fase antara kepadatan populasi prey yang berada di luar tempat persembunyian dan kepadatan populasi predator selama rentang waktu 50000 hari.

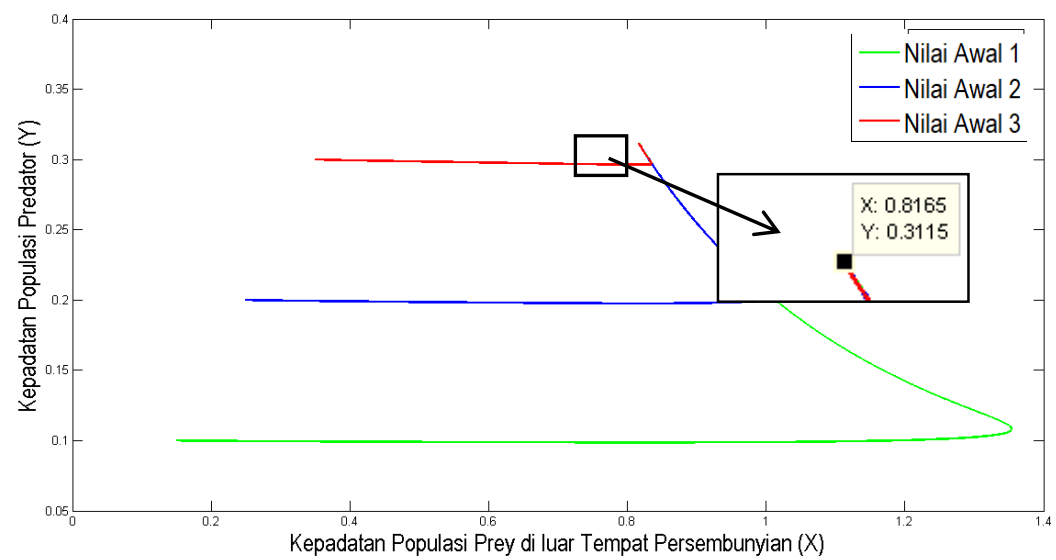

Gambar 1 Grafik Bidang Fase $x(t)$ dan $y(t)$ pada Titik Setimbang $E_{2}$ 
Pada Gambar 1 adalah grafik bidang fase kepadatan populasi prey yang berada di dalam tempat persembunyian dan kepadatan populasi predator pada model predator-prey dengan adanya faktor tempat persembunyian menggunakan fungsi respon Holling tipe III dengan syarat $E_{2}$. Berdasarkan gambar tersebut dengan ketiga nilai awal yang digunakan menunjukkan bahwa semua grafiknya cenderung menuju titik setimbang koeksistensi, yaitu titik $(0,8165 ; 0,3115)$ dengan kata lain grafik tersebut konvergen. Dengan demikian model tersebut stabil asimtotis pada titik setimbang koeksistensi.

\subsection{Simulasi Numerik}

Pada bagian ini dibahas mengenai simulasi numerik dan interpretasi model predator-prey dengan adanya faktor tempat persembunyian menggunakan fungsi respon Holling tipe III. Simulasi ini bertujuan untuk mengetahui dinamika populasi antara populasi prey yang berada di dalam tempat persembunyian, populasi prey yang berada di luar tempat persembunyian, dan populasi predator pada selang waktu tertentu.

Simulasi titik setimbang kepunahan predator merupakan simulasi numerik model predator-prey dengan adanya faktor tempat persembunyian menggunakan fungsi respon Holling tipe III yang memenuhi kondisi kestabilan titik setimbang kepunahan predator $\left(E_{1}\right)$. Nilai parameter yang digunakan untuk simulasi disajikan pada Tabel 5 dengan nilai awal $x_{r}(0)=0,30, x(0)=0,20$, dan $y(0)=0,50$ selama 500 hari.

Tabel 5 Nilai Parameter Model Predator-Prey Saat Kondisi Kepunahan Predator

\begin{tabular}{|c|c|c|}
\hline Parameter & Nilai Parameter & Sumber \\
\hline$a$ & 0,6 & Asumsi \\
\hline$K$ & 0,8 & Wang dkk (2018) \\
\hline$r$ & 1 & Asumsi \\
\hline$\alpha$ & 0,035 & Wang dkk (2018) \\
\hline$\beta$ & 0,0119 & Wang dkk (2018) \\
\hline$\gamma$ & 0,0112 & Wang dkk (2018) \\
\hline$c$ & 0,04 & Wang dkk (2018) \\
\hline$d$ & 0,007 & Asumsi \\
\hline$\xi$ & 1 & Asumsi \\
\hline$\theta$ & 0,1 & Asumsi \\
\hline
\end{tabular}

Berikut hasil simulasi yang menggambarkan dinamika populasi antara populasi prey yang berada di dalam tempat persembunyian, populasi prey yang berada di luar tempat persembunyian, dan populasi predator: 


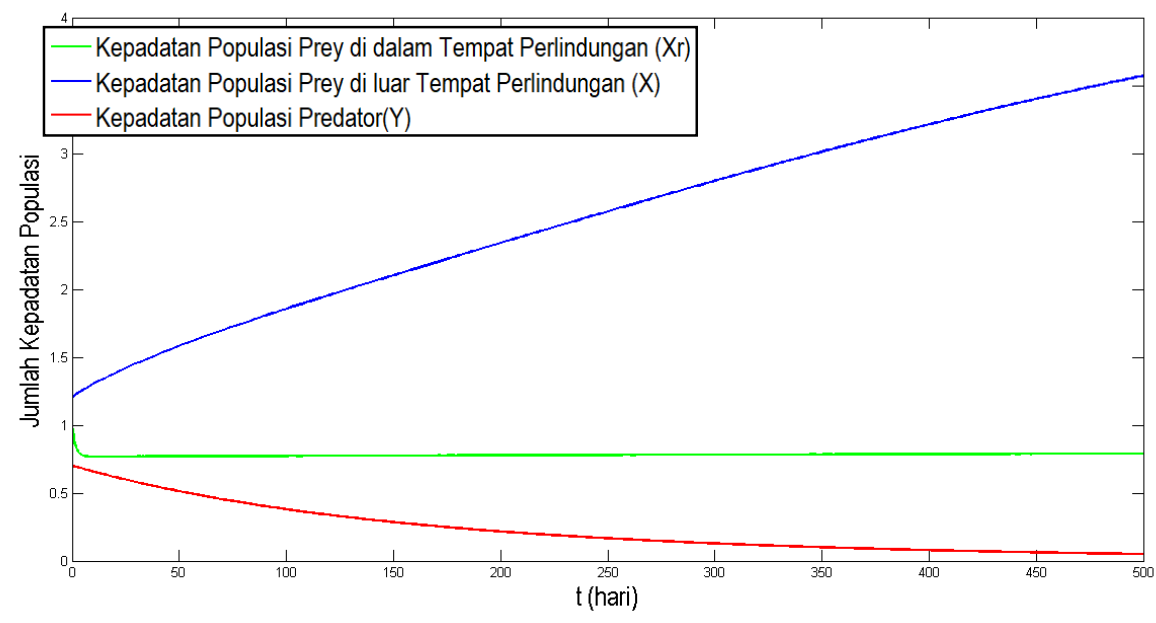

Gambar 2 Dinamika Predator-Prey Saat Kondisi Kepunahan Predator

Simulasi titik setimbang koeksistensi merupakan simlasi numerik model predator-prey dengan adanya faktor tempat persembunyian menggunakan fungsi respon Holling tipe III yang memenuhi kondisi kestabilan titik setimbang koeksistensi $\left(E_{2}\right)$. Nilai parameter yang digunakan untuk simulasi disajikan pada Tabel 4 dengan nilai awal $x_{r}(0)=0,40$, $x(0)=0,50$, dan $y(0)=0,20$ selama 5000 hari.

Berikut hasil simulasi yang menggambarkan dinamika populasi antara populasi prey yang berada di dalam tempat persembunyian, populasi prey yang berada di luar tempat persembunyian, dan populasi predator:

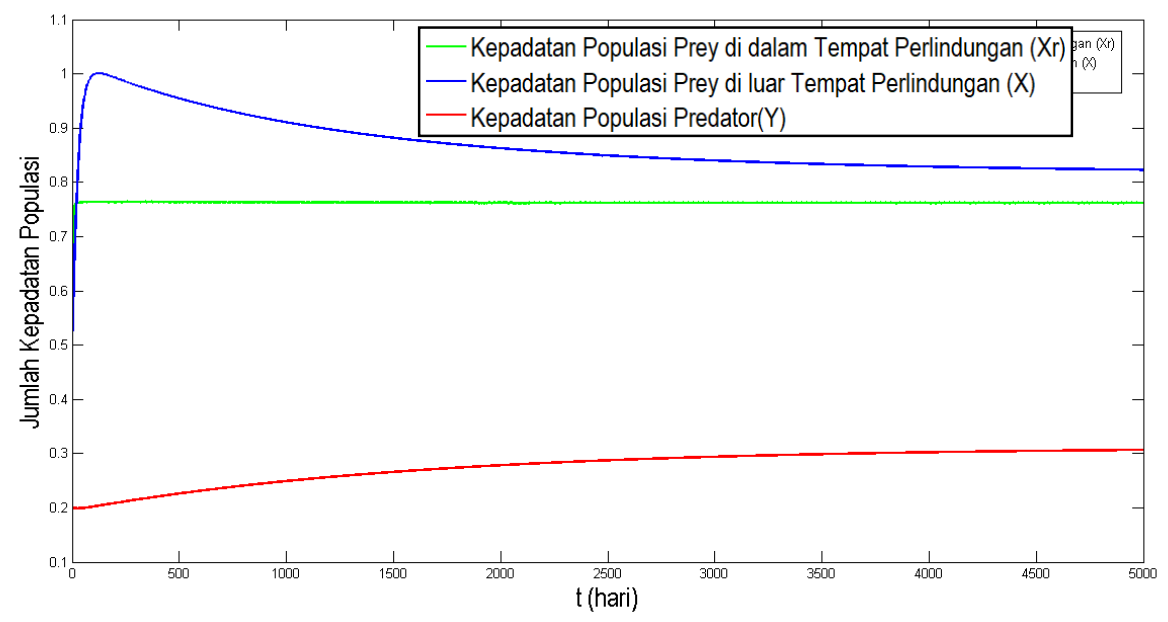

Gambar 3 Grafik Dinamika Predator-Prey Saat Kondisi Koeksistensi 


\section{Kesimpulan}

Berdasarkan hasil yang telah diperoleh pada pembahasan, dapat disimpulkan bahwa titik setimbang kepunahan bersifat tidak stabil, sedangkan titik setimbang kepunahan predator dengan syarat $\frac{c \gamma\left(\alpha K r\left(\xi^{2}+r^{2}\right)\right)^{2}}{\left(\beta r^{2}\right)^{2}+\theta\left(\alpha K r\left(\xi^{2}+r^{2}\right)\right)^{2}}<d$ dan titik setimbang koeksistensi dengan syarat koeksistensi $c \gamma-d \theta>0, a-\alpha>0, \alpha K r\left[\frac{(a-\alpha)+\sqrt{(a-\alpha)^{2}+4 \frac{a \beta r}{K\left(\xi^{2}+r^{2}\right)} x_{2}}}{2 a}\right]-\frac{\beta r^{2}}{\xi^{2}+r^{2}} x_{2}>0$ bersifat stabil asimtotis. Hasil simulasi numerik pada saat kesetimbangan kepunahan predator, kepadatan populasi prey yang berada di luar tempat persembunyian meningkat. Sedangkan pada saat kesetimbangan koeksistensi, kepadatan populasi prey yang berada di luar tempat persembunyian meningkat hingga pada waktu tertentu, lalu menurun hingga pada waktu tertentu dan selanjutnya cenderung konstan.

\section{Referensi}

[1] Kistinnah, I., dan Lestari, E.S., 2006. Biologi Makhluk Hidup dan Lingkungannya. Jakarta: Pusat Perbukuan Departemen Pendidikan Nasional

[2] Stevens, A.N.P., https://www.nature.com/scitable, 3 Oktober 2018

[3] Wang, H., Thanarajah, S., dan Gaudreau, P., 2018, Refuge-Mediated PredatorPrey Dynamics and Biomass Pyramids, Mathematical Biosciences, 298, 29-45

[4] Kar, T. K., 2006, Modelling and Analysis of A Harvested Prey-Predator System Incorporating A Prey Refuge, Journal of Computational and Applied Mathematics, 185, 19-33

[5] Dubey, B., 2007, A Prey-Predator Model with a Reserved Area, Nonlinear Analysis: Modelling and Control, 12, 279-494

[6] Wang, H., Morrison, W., Singh, A., dan Weiss, H., 2009, Modeling Inverted Biomass Pyramids and Refuges in Ecosystems, Ecological Modelling, 220, 1376-1382

[7] Berezovskaya, F. S., Song, B., dan Castillo-Chavez, C., 2010, Role of Prey Dispersal and Refuges On Predator-Prey Dynamics, SIAM J. Appl. Math., 70, 1821-1839

[8] Singh, A., Wang, H., Morrision, W.M., dan Weiss, H., 2012, Modeling Fish Biomass Structure at Near Pristine Coral Reefs and Degradation by Fishing, Journal of Biological Systems, 20, 21-36

[9] Abell, M. dan Braselton, J.,2004, Differential Equations with Mathematica, Third Edition, USA: Elsevier Academic Press 